University of South Carolina

Scholar Commons

$12-2009$

\title{
Improved Hydrogeophysical Parameter Estimation from Empirical Mode Decomposition Processed Ground Penetrating Radar Data
}

Adrian Addison

University of South Carolina - Columbia

Bradley M. Battista

Camelia C. Knapp

University of South Carolina - Columbia, camelia@geol.sc.edu

Follow this and additional works at: https://scholarcommons.sc.edu/geol_facpub

Part of the Earth Sciences Commons

Publication Info

Published in Journal of Environmental and Engineering Geophysics, Volume 14, Issue 4, 2009, pages 171-178.

Addison, A. D., Battista, B. M., \& Knapp, C. C. (2009). Improved hydrogeophysical parameter estimation from empirical mode decomposition processed ground penetrating radar data. Journal of Environmental and Engineering Geophysics, 14 (4), 171-178.

(C) Journal of Environmental and Engineering Geophysics 2009, Society of Exploration Geophysicists

This Article is brought to you by the Earth, Ocean and Environment, School of the at Scholar Commons. It has been accepted for inclusion in Faculty Publications by an authorized administrator of Scholar Commons. For more information, please contact digres@mailbox.sc.edu. 


\title{
Improved Hydrogeophysical Parameter Estimation from Empirical Mode Decomposition Processed Ground Penetrating Radar Data
}

\author{
Adrian D. Addison, Bradley M. Battista and Camelia C. Knapp \\ Department of Geological Sciences, University of South Carolina, 701 Sumter St. EWS 617, \\ Columbia, South Carolina 29208 \\ Email: aaddison@geol.sc.edu
}

\begin{abstract}
Various techniques have been designed to maximize the use of ground penetrating radar (GPR) as an exploration tool. Improvements in signal processing are expected to further facilitate the accuracy of parameters derived from using GPR in certain geologic environments. Common-offset GPR data were collected at the Marine Corps Air Station (MCAS) in Beaufort, South Carolina, and dielectric constants were calculated following the application of the empirical mode decomposition (EMD) for dewowing GPR traces. Conventional signal processing is applied to the GPR traces to provide hydrogeophysical parameter estimates such as volumetric water content, porosity, and hydraulic conductivity. The results are validated using a coincident vertical radar profile, existing hydraulic data from direct measurements, and comparing EMD derived parameters with those non-EMD derived. The results of the comparison between the EMD and non-EMD methods show improved hydrogeophysical estimations from the EMD processed data. Dielectric constant $(k)$ values from the non-EMD method are outside the range of the values for all geologic materials $(k \leq 40)$. The subsequent parameter estimates using dielectric constants derived from non-EMD processed data yield erroneous results therefore justifying the use of EMD as a method in dewowing GPR data for quantitative analyses.
\end{abstract}

\section{Introduction}

In the field of hydrogeophysics, ground penetrating radar (GPR) is just one tool utilized to calculate hydrogeophysical parameters such as volumetric water content, porosity and hydraulic conductivity (Gloaguen et al., 2001). These hydrogeophysical parameters are critical in generating an accurate ground water model, especially in the case of contaminant flow prediction. Standard methods for calculating these parameters are a result of slug and aquifer testing, grain size and sieve analysis, and general information from the geology at a site (Rhine and Shafer, 2000; Siple, 1960; and Spigner and Ransom, 1979). Boreholes are needed to complete such work, which are expensive and provide point data whereas ground water flow problems are two-and threedimensional. Hydrogeophysical parameters estimated from geophysical data, in conjunction with boreholederived parameters, are important because of their general low cost, ease of acquisition, and capability to cover larger spatial areas than boreholes.

Supporting studies in hydrogeophysical parameter calculation include work from Topp et al. (1980),
Gloaguen et al. (2001), and Hubbard et al. (1997). Work in parameter estimation starts with Topp et al. (1980), where they empirically derived the relationship between electromagnetic waves and volumetric water content. Several equations, such as the relationship between velocity, dielectric constants, and volumetric water content, were utilized in the application portion of this paper. Hubbard et al. (1997) used the CRIM relation in estimating hydrogeophysical parameters that relates electromagnetic velocity to volumetric water content. In estimating hydrogeophysical parameters, crosshole radar is the preferred method because of the uncertainty of the electromagnetic velocity at depth in the surface radar data. However, Gloaguen et al. (2001) demonstrate that the use of surface GPR in parameter calculation is possible by knowing the depths to interfaces and matching them to the GPR reflections. Gloaguen et al. (2001) estimated hydraulic conductivity using surface GPR data and hydrostratigraphic data, created synthetic GPR sections to further match the interfaces to reflections, as well as used the KozenyCarman relation (Freeze and Cherry, 1979) to calculate hydraulic conductivity. This work is dependent upon 
Journal of Environmental and Engineering Geophysics

accurate velocity estimation, which in turn affects the dielectric constant estimation.

The results from Battista et al. (2009) describe the benefits of using data-driven empirical mode decomposition (EMD) to dewow GPR traces before ensuing any conven-tional processing. The reasons for using EMD to dewow GPR traces are that WOW noise 1) varies from trace to trace, and 2) is not well defined and requires a data-driven, time-domain operator for complete removal. Standard dewowing uses a time-domain operator (Gerlitz et al., 1993) that requires trace-by-trace design. The EMD method both precludes this requirement and preserves signal attributes. The results are dielectric constants of higher accuracy and greater precision on the premise that WOW noise is more completely removed. Following dewow, an amplitude gain function is the only significant processing step applied. The need for further processing is insignificant considering the traces were acquired with high power and resolution. We support Kutrubes et al. (1994) and Oldenborger et al. (2004) premises that signal attributes required for quantitative analysis of GPR data are highly sensitive to processing, and that a minimal approach should be taken in processing for quantitative results. This paper is focused on the subsequent use of the dielectrics to calculate and make comparisons of hydrogeophysical parameters derived from EMD and non-EMD processed data.

\section{Study Area and Hydrogeologic Setting}

The Marine Corps Air Station (MCAS) is located near the city of Beaufort, South Carolina in the Atlantic Coastal Plain (Fig. 1). The geology and hydrogeology of the Beaufort area was determined by Siple (1960) and Spigner and Ransom (1979). A contamination vulnerability study by Rhine and Shafer (2000) that was completed in 2000 by Earth Sciences and Resources Institute (ESRI) of the University of South Carolina further detailed the geology and hydrogeology of the air station (Fig. 2). GPR data were collected to complement the previous study, which included electrical conductivity, vertical radar profiling, seismic reflection data, and gamma logs. This particular site was chosen for this study because the geologic setting is ideal for radar data collection because of the presence of sands.

Since the MCAS site is located within the Atlantic Coastal Plain, Pleistocene sands are the predominant sediments which overlie the Eocene Ocala limestone (Siple, 1960). This information was determined through previous works by Siple (1960) and Spigner and Ransom (1979), core descriptions and geophysical logs such as natural gamma. The cores from well BFT-2368 show sands with very little clay content. The water table is

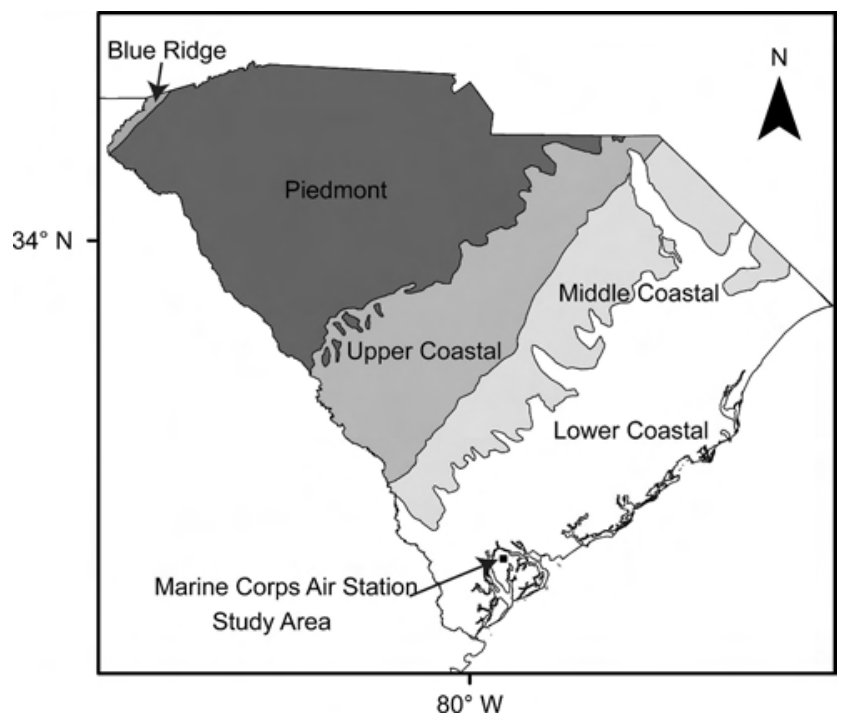

Figure 1. Study area and location of Marine Corps Air Station (Beaufort, SC) with geomorphic provinces of South Carolina.

located at approximately 5-6 $\mathrm{m}$ below land surface (bls) (Rhine and Shafer, 2000) (Fig. 3). The core descriptions along with the geophysical logs were later used to correlate depths in the surface GPR section.

The hydrogeologic setting consists of two aquifers; 1) a shallow aquifer (0-22 $\mathrm{m}$ bls) and 2) the Upper Floridian aquifer (starting at $22 \mathrm{~m}$ bls) (Siple, 1960). The Floridian aquifer is widely known and studied (Siple, 1960) (Fig. 3). The units in this section are the Surficial Sand, the Lower Sand, the Basal Sand, the Upper Floridian and the Middle Confining units (Spigner and Ransom, 1979). The Surficial Sand is the upper most unit $(0-10 \mathrm{~m}$ bls $)$, and contains the shallow water table (5-6 m bls). Between a depth of $10 \mathrm{~m}$ to $16 \mathrm{~m}$ bls lies the Lower Sand unit with the Basal Sand unit below from 16 to $24 \mathrm{~m}$ bls. The Upper Floridian and the Middle Confining units make up the portion of the Floridian aquifer between 24 to $35 \mathrm{~m}$ bls (Rhine and Shafer, 2000).

\section{Methods}

Ground penetrating radar theory is described by the Maxwell equations and the derivation of these equations can be found in any electromagnetic theory text, but it was introduced for geophysical application primarily by (Davis and Annan, 1989). This study focuses on the wave and physical properties as they relate to GPR and water. In the dielectric constant calculations process, an assumption is made that the environment is a low-loss medium due to the high amplitude and coherent reflections present in the data. 
Addison et al.: Application of EMD to GPR Data
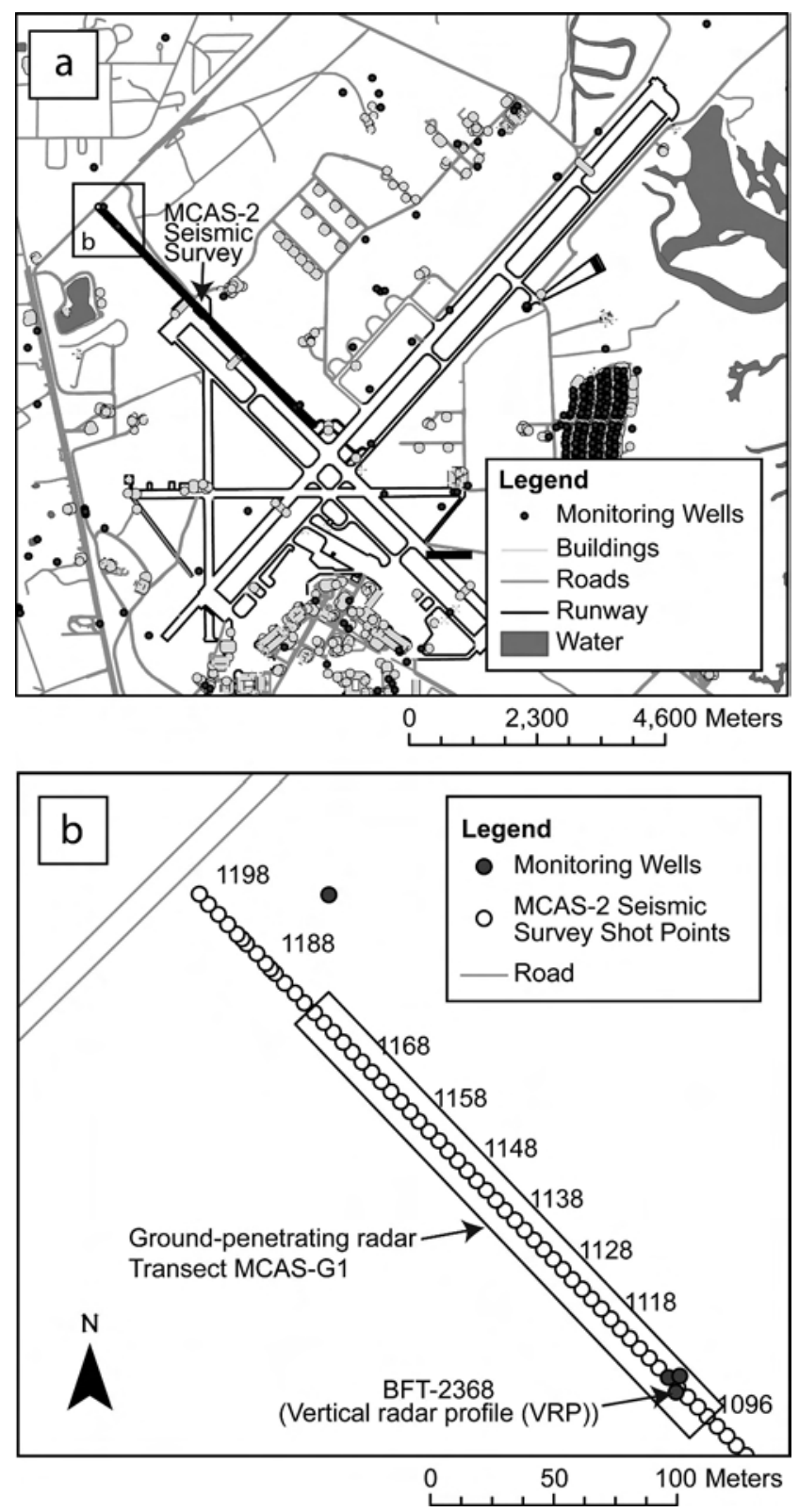

Figure 2. Close-up of Marine Corps Air Station (Beaufort, SC) study area (a), ground-penetrating radar transect (MCAS-G1), well BFT-2368, and MCAS-2 seismic line shot points (b).

In a low-loss environment, the velocity of the electromagnetic waves can be written as:

$$
v=\frac{\omega}{\beta} \approx \sqrt{\frac{1}{k \mu_{0} \varepsilon_{0}}},
$$

where $k=\varepsilon / \mathrm{c}$ is the relative permittivity or dielectric constant, $\omega$ is the angular frequency, $\mu_{o}$ is the magnetic permeability in free space, $\varepsilon_{\mathrm{O}}$ is the permittivity in a vacuum, and $\beta$ is the phase constant (Annan, 2005). In GPR, dielectric permittivity is the material's response to

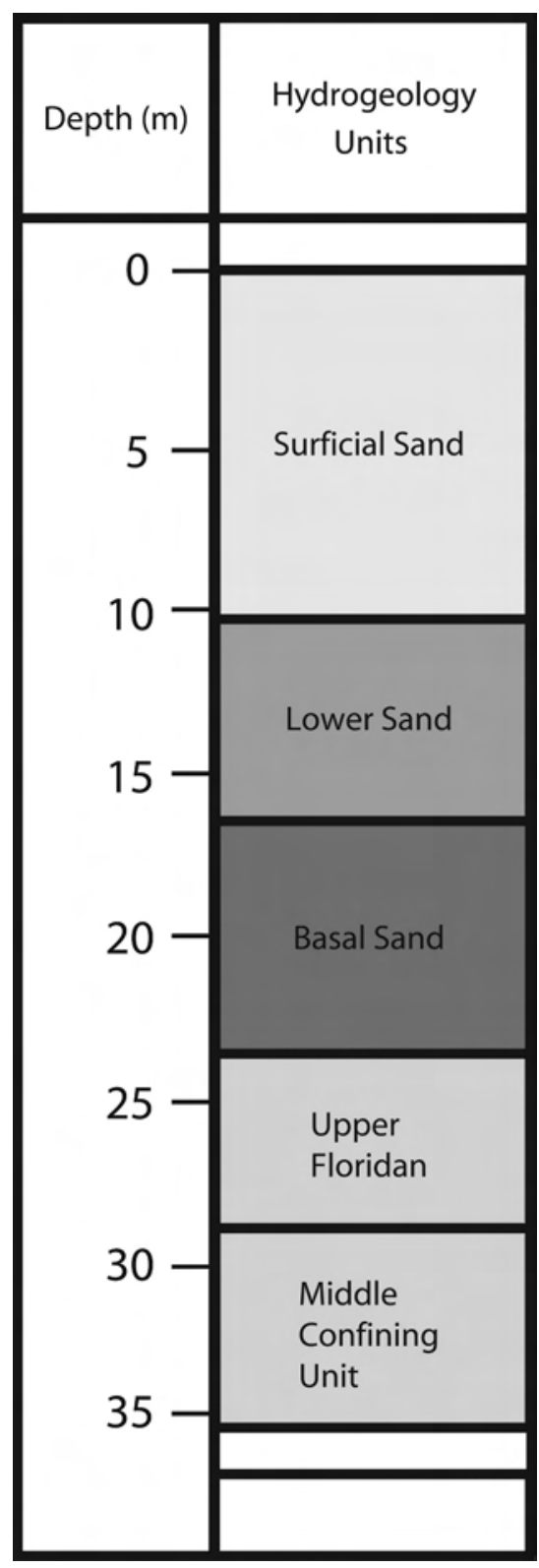

Figure 3. Lithologic and hydrologic information for well BFT-2368 (shown in Fig. 2), modified from Rhine (2000).

the electromagnetic energy and is often referred to as "relative permittivity" or "dielectric constant" (Annan, 2005). Further simplification of Eq. 1 to Eq. 2, by removing the magnetic permeability and attenuation components, can be done by assuming a low-loss environment and materials with little or no ferric components (Annan, 2005):

$$
k \approx\left(\frac{\mathrm{c}}{\mathrm{v}}\right)^{2}
$$

where $\mathrm{c}$ is the electromagnetic velocity in a vacuum (or air) and $v$ is the electromagnetic velocity of the medium. To have a reflection in GPR data, there must be layers 
Journal of Environmental and Engineering Geophysics

with contrasting electrical properties so the radar wave can be divided into a transmitted and reflected wave. The amplitude of the resulting reflected wave is dependent upon the reflection coefficient, $R C_{n}$ :

$$
\begin{gathered}
R C_{n}=\frac{\sqrt{k_{n}+1}-\sqrt{k_{n}}}{\sqrt{k_{n}+1}+\sqrt{k_{n}}}, \\
k_{n}+1=k_{n}\left(\frac{1+R C_{n}}{1-R C_{n}}\right)^{2},
\end{gathered}
$$

where $k_{n}$ is the dielectric constant of the medium (Young, 2002). Once the dielectric constants are calculated (Eqs. 3 and 4), the next step is to place the values into the empirically derived equation by Topp et al. (1980) (Eq. 5), which relates the volumetric water content $\left(V_{w c}\right)$ to the dielectric constants:

$$
\begin{aligned}
V_{w c}= & -5.3+2.92(k)^{2}-5.5 \times 10^{-2}(k)^{4}+4.3 \\
& \times 10^{-4}(k)^{6} .
\end{aligned}
$$

The porosity $(\Phi)$ of the saturated zone can be estimated based on the assumption that 100 percent saturation is equal to the pore spaces being completely filled or that porosity is equal to $V_{w c} / 100$ (Topp et al., 1980). The porosity for the unsaturated zone can be calculated, but was not in this study because of the need for further laboratory testing and results (Gloaguen et al., 2001).

Hydraulic conductivity was calculated by using the Kozeny-Carmen equation from Bear (1972):

$$
K=\left(\frac{\rho g}{\mu}\right)\left[\frac{n^{3}}{(1-n)^{2}}\right]\left(\frac{d_{m}^{2}}{180}\right),
$$

where $\rho\left(\mathrm{kg} / \mathrm{m}^{3}\right)$ is the fluid density, $\mu(\mathrm{kg} / \mathrm{ms})$ is the viscosity, $g\left(\mathrm{~m} / \mathrm{s}^{2}\right)$ is the acceleration due to gravity, $n$ is the porosity (estimated from GPR data), and $d_{m}(\mathrm{~m})$ is the representative grain size. For this project, the values were $\rho=999.7 \mathrm{~kg} / \mathrm{m}^{3}$ (at a temperature of $10^{\circ} \mathrm{C}$ ), $\mu=1.307 \times$ $10^{-3} \mathrm{~kg} / \mathrm{ms}$ (at a temperature of $10^{\circ} \mathrm{C}$ ),$g=9.81 \mathrm{~m} / \mathrm{s}^{2}$, and $d_{m}=0.0002 \mathrm{~m}$ (based on dry sieve data).

Seismic reflection and vertical seismic profiling (VSP) data, as well as electrical conductivity and gamma logs, were collected to interpret subsurface lithological units within the study area. The electrical conductivity and natural gamma logs correlate well with the lithological units, the Ocala Limestone, top of the Basal Sand and the top of the Lower Sand units. A common offset GPR transect (MCAS-G1), using $100 \mathrm{MHz}$ antennas from the PulseEKKO 100 system by Sensors \& Software, was collected coincident with the seismic reflection line MCAS-2 (Fig. 2). In common offset acquisition, the transmitter and the receiver antennas are maintained at a fixed separation distance $(1 \mathrm{~m})$ and then moved by a set distance $(0.25 \mathrm{~m})$. Vertical radar profiling (VRP) data were collected in borehole BFT2368 along the MCAS-2 seismic profile to allow calculating velocities, volumetric water content, attenuation, and electrical conductivity; however, for this paper only the velocities were used. Transect MCAS-G1 was used for EMD testing, and the processing steps were completed in Matlab ${ }^{\mathrm{TM}}$ using the following flow: 1) WOW removal, 2) amplitude correction for spherical spreading loss, 3) pick horizons (in time) for changes in velocity, and 4) conversion of reflection coefficients to dielectric constants. Two parallel processing flows were applied to the MCAS-G1 data with the exception of the application of the dewow filter. In one flow the EMD was applied, whereas a commonly used moving average filter was applied to the other flow. The only processing beyond the dewow filtering was the amplitude correction for the spherical spreading loss.

We interpreted the surface GPR section in time based on the knowledge of the geologic setting and the velocity profile from the VRP data. Three zones were interpreted (see Fig. 4): 1) Unsaturated Surficial Sand, 2) Saturated Surficial Sand, and 3) Saturated Lower Sand. At the interface of the zones there are strong reflections of high amplitude indicating changes in the dielectric constants from zone to zone. As compared to the interfaces, within the zones there are reflections of weaker amplitude indicating smaller changes in dielectric constants. Since there are large changes at the interfaces, a different velocity was used to calculate the $k_{n}$ in Eq. 2 for each zone. By inputting the velocities we could account for the large decrease in velocity between the unsaturated and saturated zones and maintain the small changes in dielectric constants within each zone. The velocities for Eq. 2 were chosen based on the table of electromagnetic velocities for geologic materials in Davis and Annan (1989). Two velocity values were assigned: 1) a dry sand and 2) a wet sand. Table 1 compares the two-way travel time, VRP velocities, and GPR velocities used in the parameter estimation. The comparison will be discussed in further detail in the results section.

\section{Results}

Before the calculation of the parameters, we wanted to compare the velocities chosen from the Davis and Annan (1989) table with that from the VRP data. With the exception of the Lower Sand zone, our velocities are nearly the same. The comparison is a validation that the chosen velocities are adequate for parameter estimation. Calculation of the dielectric constants is performed following the EMD and nonEMD-based dewow with a spherical divergence gain recovery applied to both. Two zones are selected for analysis; these are the Saturated Surficial Sand unit (67 

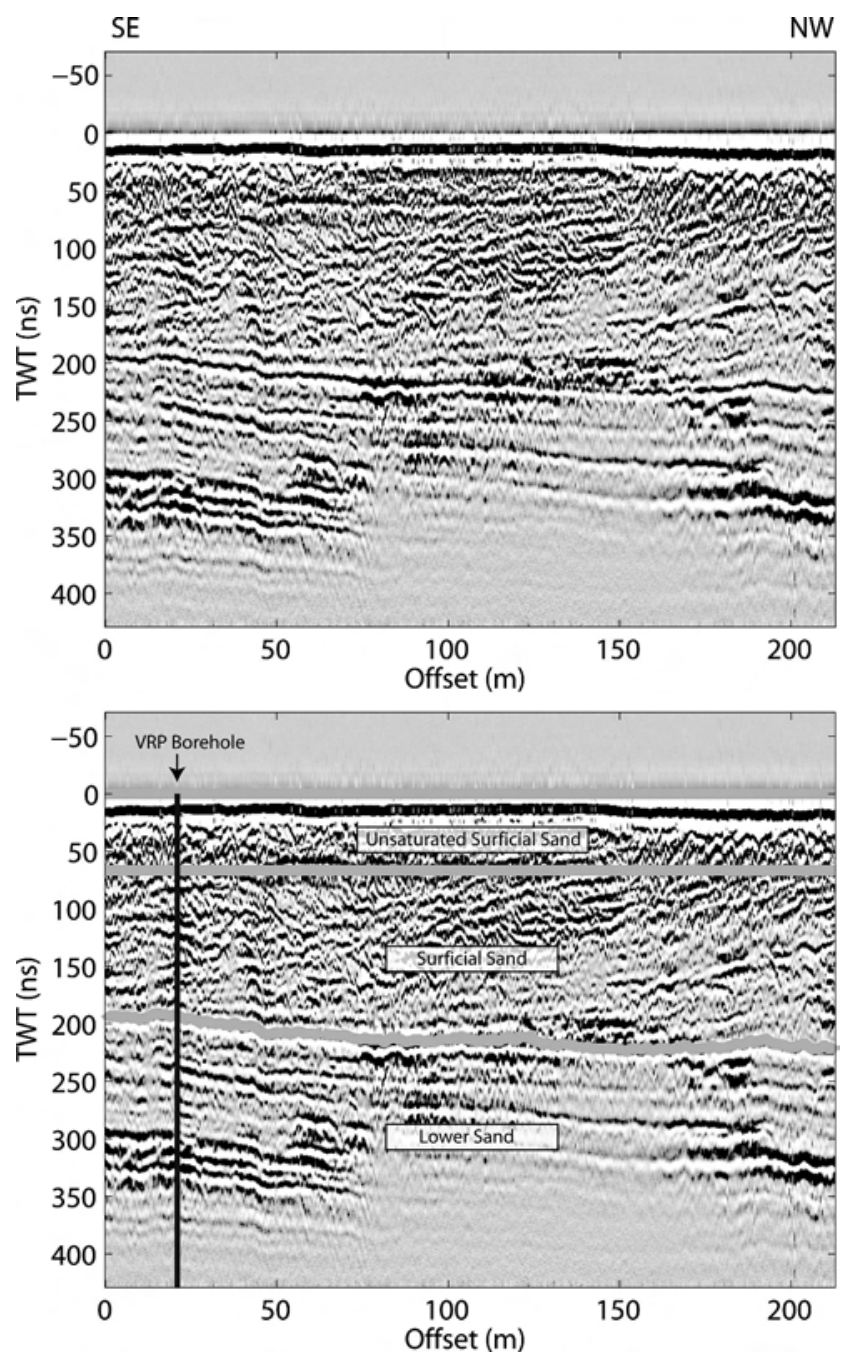

Figure 4. Interpretation of ground-penetrating radar transect MCAS-G1 (shown in Fig. 2) with hydrogeologic layers used for dielectric constant estimation.

to $200 \mathrm{~ns}$ ) and the Saturated Lower Sand unit (200 to $450 \mathrm{~ns})$ seen in Fig. 4. The unsaturated portion of the section in the Surficial Sand unit was not used in the calculation of dielectric constants because of the difficulties associated with the conversion from volumetric water content to porosity, which required further information. The dielectric constant (Fig. 5) values were restricted to the range of 0 to 40 for each method since 40 is the maximum value for a dielectric constant of any geologic material. Generally, most of the values are between 0 and 40, but the non-EMD method is less stable than the EMD method with values higher than a thousand. Taking a closer look at the two sections of the non-EMD data (Fig. 5), the values for the Surficial Sand are centered around 25 while the values for the Lower Sand are approximately centered around 35. Note that there are more columns of unstable values,
Table 1. Two-way travel time, vertical radar profile (VRP) velocity, and ground-penetrating radar (GPR) velocity along GPR profile (Marine Corps Air StationGPr-1) MCAS-G1.

\begin{tabular}{lccc}
\hline \hline \multicolumn{1}{c}{ Zone } & $\begin{array}{c}\text { Two-way } \\
\text { Time } \\
\text { (ns) }\end{array}$ & $\begin{array}{c}\text { VRP } \\
\text { Velocity } \\
\text { (m/ns) }\end{array}$ & $\begin{array}{c}\text { GPR } \\
\text { Velocity } \\
\text { (m/ns) }\end{array}$ \\
\hline Unsaturated Surficial Sand & 0 to 67 & 0.15 & 0.15 \\
Surficial Sand & 0 to 200 & 0.06 & 0.06 \\
Lower Sand & 200 to 450 & 0.055 & 0.06 \\
\hline
\end{tabular}

values that are outside the range of those expected for the geologic setting (30-40), in the non-EMD method calculations than in the EMD. Between offsets 175 and 200 in the Saturated Surficial Sand zone of the nonEMD section, there are columns with values centered on 15 and 25 , surrounded by values of a thousand or more.

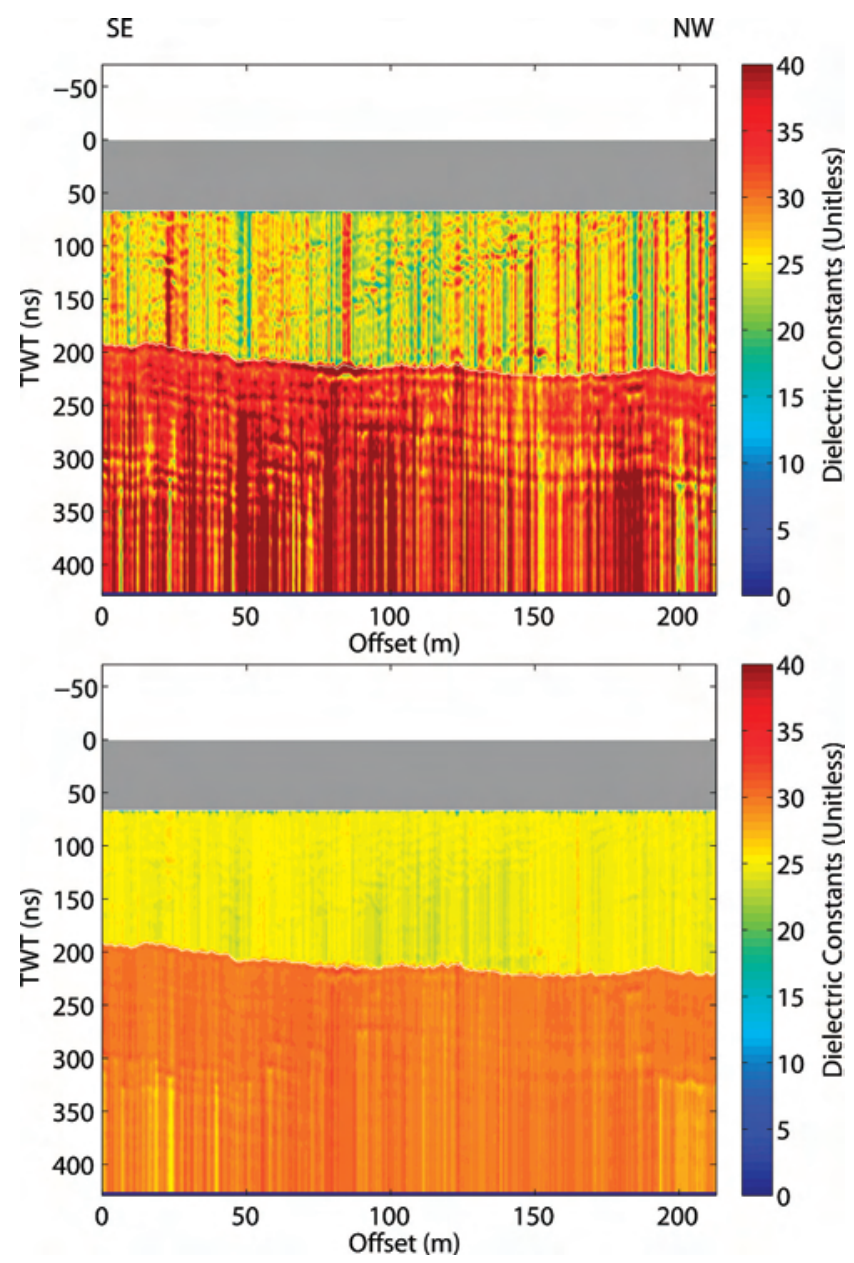

Figure 5. Dielectric constants derived from processed ground-penetrating radar transect MCAS-G1 (shown in Fig. 4) with non-EMD (top) and EMD (bottom) techniques applied. 
Journal of Environmental and Engineering Geophysics

The Lower Sand zone of the non-EMD section has a similar issue as the Surficial zone, with values exceeding a thousand outside the expected range of $0-40$ for geologic materials (Davis and Annan, 1989). The EMD section shows values centered around 25 for the Saturated Surficial Sand zone and values centered around 30 for the Saturated Lower Sand zone. The EMD section has variations within the two zones but no anomalous values, in fact all EMD-derived values are less than 35.

A linear conversion from the dielectric constants to volumetric water content was made using Eq. 5. The section was treated in the same manner as the dielectric estimation, with calculations made for two zones, resulting in $V_{w c}$ values ranging from 0 to $50 \%$. Upper limit restrictions were imposed because of the anomalous values caused by the non-EMD processed data (Fig. 6). The instability of the non-EMD method is evident by the columns of values outside the average ( $40 \%$ for the Saturated Surficial Sand and $45 \%$ for the Saturated Lower Sand) for each zone. Since the anomalous dielectric values from the non-EMD method were used in the volumetric water content calculation, the resulting figure shows the Saturated Surficial and Saturated Lower Sand zones having nearly equal values. The difference between the EMD and the non-EMD methods is that the EMD processed sections have more stable values. The more stable values of the EMD method do not over load the volumetric water content values, and the Surficial and Lower Sand zones have an average $V w c$ value of $25 \%$ and $30 \%$, respectively.

The $V_{w c}$ range of $0-50 \%$ calculated for the two saturated sand zones corresponds to a range in porosity of 0 to 0.5 . In the EMD processed data, the porosity value of 0.25 for the Saturated Surficial Sand is reasonable based on the previous work by Rhine and Shafer (2000) (value of 0.3). Using the GPR-derived porosity values to estimate hydraulic conductivity (Eq. 6) yields hydraulic conductivity values ranging from 0 to $50 \mathrm{~m} /$ day for the non-EMD method, and 25 to $45 \mathrm{~m} /$ day for the EMD method.

GPR-derived hydraulic conductivities using both the non-EMD and EMD methods were compared to each other, and to measured hydraulic conductivity values obtained during previous work at the site for validity. Previously, a groundwater vulnerability study measured the hydraulic conductivity for the entire MCAS study area using two types of data: 1) slug test and 2) grain size analysis. The grain size analysis typically overestimates the hydraulic conductivity while the slug test underestimates the value, thus the wide range of values for the site (Rhine and Shafer, 2000). The values ranged from $1.5 \mathrm{~m} /$ day to $21.3 \mathrm{~m} /$ day, with the GPR-derived hydraulic conductivity values within an order of magnitude of the measured values.

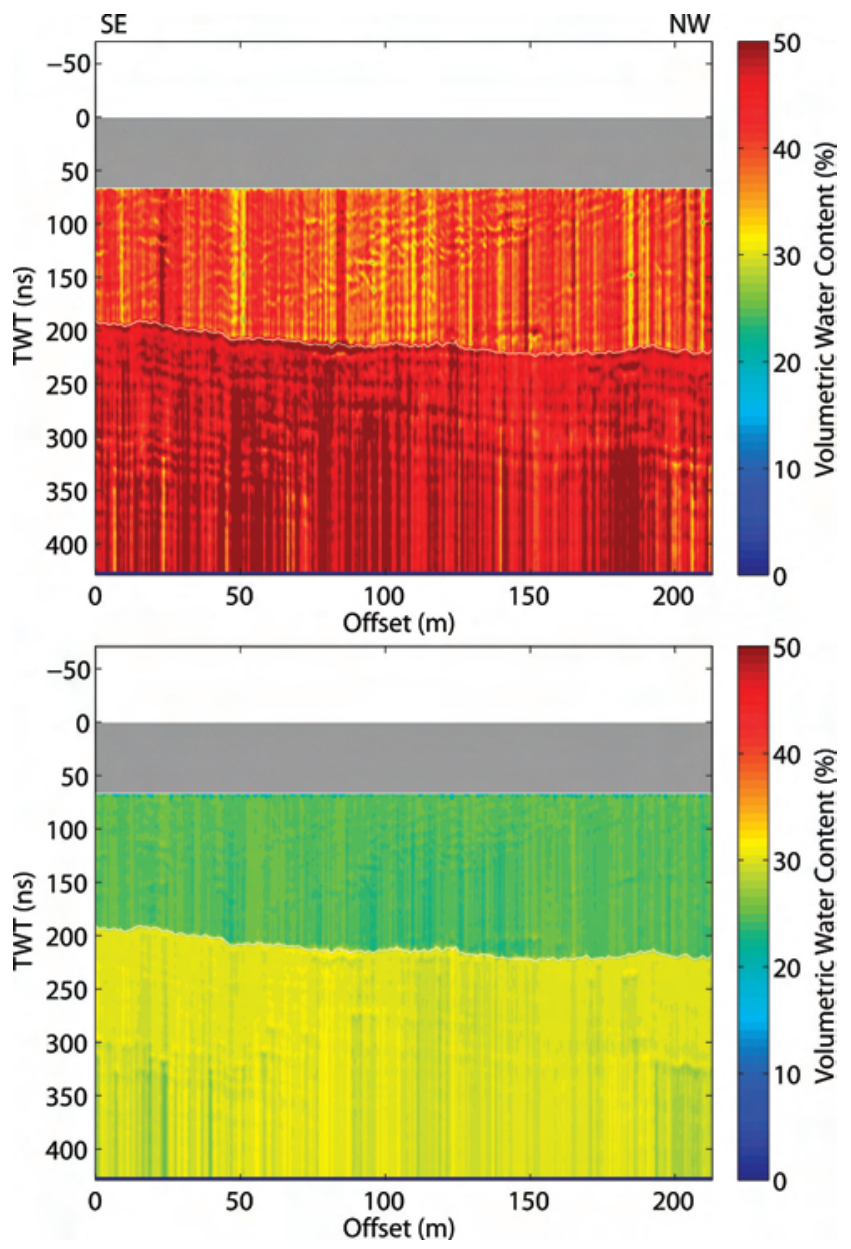

Figure 6. Volumetric water content values calculated from processed ground-penetrating radar transect MCAS-G1 (shown in Fig. 4) with non-EMD (top) and EMD (bottom) techniques applied.

Hydraulic conductivity values vary within the Saturated Surficial Sand unit from 10 to $55 \mathrm{~m} /$ day, and 20 to $55 \mathrm{~m} /$ day for the Saturated Lower Sand unit (Fig. 7) in the non-EMD dataset; however, values were clipped at $55 \mathrm{~m} /$ day because of the anomalous values that exceeded $1,000 \mathrm{~m} /$ day. For the EMD method the values are more stable, being from 25 to $35 \mathrm{~m} /$ day for the Surficial Sand unit, and 35 to $45 \mathrm{~m} /$ day for the Lower Sand unit (Fig. 7).

\section{Conclusions}

The goal of this research was to find a methodology that yields more accurate parameter estimation than the standard GPR data processing. Another goal of this research was to supply researchers working in the fields of groundwater hydrogeology and near-surface geophysics with a tool for quickly processing surface 
Addison et al.: Application of EMD to GPR Data

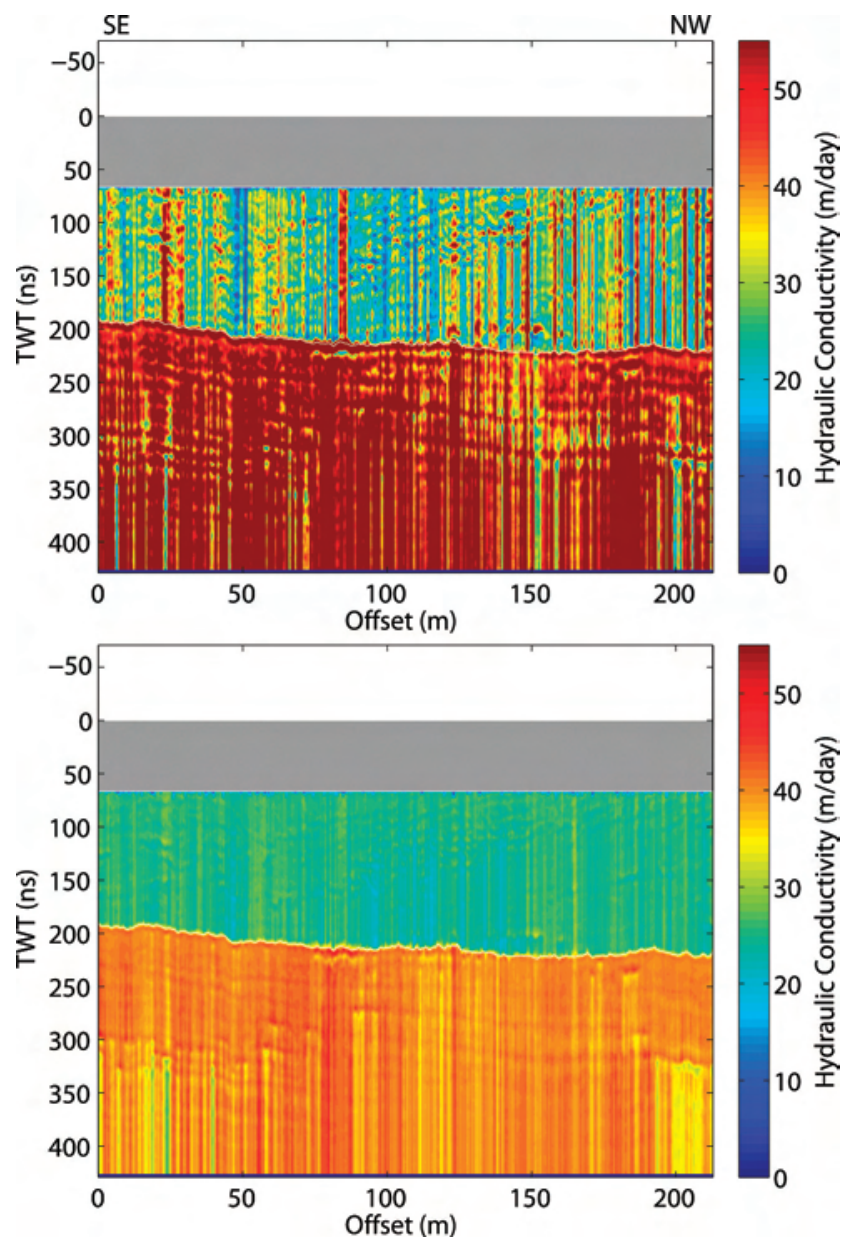

Figure 7. Hydraulic conductivity (m/day) calculation from processed ground-penetrating radar transect MCAS-G1 (shown in Fig. 4), with non-EMD (top) and EMD (bottom) techniques applied.

GPR data for use in the calculation of hydrogeophysical parameters. A comparison between the EMD and nonEMD data processing indicates that the EMD method yields better results for hydrogeophysical parameter estimation. The EMD-derived dielectric constant values are more accurate and show less error, with more stable calculated values than the non-EMD data. As expected, the calculation of hydrogeophysical parameters, such as volumetric water content, porosity, and hydraulic conductivity, from those dielectric constants yielded similar results, i.e., the EMD method provides stable values (values representative of the geologic setting) versus anomalous values of the non-EMD method. The volumetric water content and the porosity contain similar results in that the EMD values are more precise and less scattered, while the non-EMD values are scattered with values exceeding 40, which is greater than the values from previous studies in the study area. The final comparison is between the EMD and non-
EMD calculated hydraulic conductivity, which also maintained the consistent pattern of varying value ranges as the dielectric constants, volumetric water content, and porosity. The values of the EMD-derived hydraulic conductivity compare favorably with those from a previous study.

\section{Acknowledgements}

We would like to acknowledge the following individuals and groups; Craig Ehde from the Natural Resources and Environmental Affairs Office (NREAO), Marine Corps Air Station Beaufort, South Carolina, Michael Waddell from the Earth Sciences and Resources Institute (ESRI), and the Geophysical Exploration and Tectonics Geophysical Laboratories (GEL and TGL) of the University of South Carolina.

\section{References}

Annan, A.P., 2005, Hydrogeophysics, chapter 7: in GPR methods for hydrogeological studies: Springer, $523 \mathrm{pp}$.

Bear, J., 1972. Dynamics of fluids in porous media: American Elsevier, New York, 784 pp.

Davis, J., and Annan, A.P., 1989, Ground-penetrating radar for high resolution mapping of soil and rock stratigraphy: Geophysical Prospecting, 37, 531-551.

Freeze, R., and Cherry, J., 1979. Groundwater: Prentice-Hall, Inc., $604 \mathrm{pp}$.

Gerlitz, K., Knoll, M.D., Cross, G.M., Luzitano, G.M., and Knight, R., 1993, Processing ground penetrating radar data to improve resolution of near-surface targets: in Proceedings of the Symposium on the Application of Geophysics to Engineering and Environmental Problems, 564-565.

Gloaguen, E., Chouteau, M., Marcotte, D., and Chapuis, R., 2001, Estimation of hydraulic conductivity of an unconfined aquifer using cokriging of gpr and hydrostratigraphic data: Applied Geophysics, 47, 135-152.

Hubbard, S., Rubin, Y., and Majer, E., 1997, Groundpenetrating-radar-assisted saturation and permeability estimation in bimodal systems: Water Resources Research, 33, 971-990.

Kutrubes, D.L., Zhang, J., and Mackie, R.L., 1994, Determination of gpr processing capabilities using Promax: in Expanded Abstracts: Proceeding of the IEEE Dual-Use Technologies and Applications Conference, 439-446.

Oldenborger, G.A., Knoll, M.D., and Barrash, W., 2004, Effects of signal processing and antenna frequency on the geostatistical structure of ground-penetrating radar data: Journal of Environmental and Engineering Geophysics, 9, 201-212.

Rhine, J., and Shafer, J., 2000, Groundwater characterization report: three dimensional groundwater flow and flow path analysis: Technical report, Earth Sciences and Resources 14 Institute, University of South Carolina. Aquifer vulnerability and contamination potential assessment at U.S. Marine Corps Air Station, Beaufort, South Carolina. 
Journal of Environmental and Engineering Geophysics

Siple, G., 1960. Geology and ground water conditions in Beaufort area, South Carolina, U.S. Geological Survey, Columbia, South Carolina.

Spigner, B., and Ransom, C. III, 1979, Report on groundwater conditions in the low county area, South Carolina: Technical Report 132, South CarolinaWater Resources Commission, Columbia, South Carolina.
Topp, G., Davis, J., and Annan, A.P., 1980, Electromagnetic determination of soil water content: measurements in coaxial transmission lines: Water Resources Research, 16, 574-582.

Young, C., 2002, Estimating hydrogeologic parameters from radar data http://www.geo.mtu.edu/profile/CTYOUNG. HTM. 